\title{
Household Factors Affecting the Implementation of Forest Conservation Strategies: A Case of South Nandi Forest, Nandi County, Kenya
}

\author{
Charles Kiprono Koech ${ }^{1,2}$ \\ ${ }^{1}$ College of Humanities and Social Sciences, Faculty of Arts, Department of Sociology and Social Work, University of Nairobi, \\ Nairobi, Kenya \\ ${ }^{2}$ Kenya Forestry Research Institute (KEFRI), Nairobi, Kenya \\ Email: koechkiprono12@gmail.com
}

How to cite this paper: Koech, C. K. (2020). Household Factors Affecting the Implementation of Forest Conservation Strategies: A Case of South Nandi Forest, Nandi County, Kenya. Open Journal of Social Sciences, 8, 125-144.

https://doi.org/10.4236/jss.2020.86012

Received: April 27, 2020

Accepted: June 7, 2020

Published: June 10, 2020

Copyright $\odot 2020$ by author(s) and Scientific Research Publishing Inc. This work is licensed under the Creative Commons Attribution International License (CC BY 4.0).

http://creativecommons.org/licenses/by/4.0/

\begin{abstract}
This study found out that the majority of the locals are not employed. They may end up encroaching into the forest for the activities that will generate some income for them. The majority of the locals earn less than US dollars 100 which are not enough to take care of their loved ones. Daily expenditure is not good enough to satisfy their needs which are likely to tempt them to encroach into the forest. The forest provides a good source of firewood since it is the source of fuel that the locals mostly use, thus inhibiting strategies that may lead to stopping them from over harvesting from the forest. The study found out that for forest conservation to be effective, more motivation is needed and more of training should be done to educate people about the importance of forests, the need to conserve them and how to conserve them. For better handling of the challenges on implementation of forest conservation measures, there should be full involvement of local community in forest conservation. Barazas are the ideal method of communication through which information regarding forest conservation is gotten and they should make sure that many people are involved in planning and implementation of forest conservation activities. With more efforts from the relevant authorities, it's easy to converse the forest and make sure that tree planting is the best way of planning and implementation of forest conservation activities. Through forest conservation and proper management, the forest can be very beneficial to many that stay around without destroying it. The local authorities can use the available environmental groups to enlighten the community on the importance of forest conservation. The study found out deforestation through illegal logging, charcoal burning, and the encroachment of forests for human settlement and
\end{abstract}


agriculture. These problems are compounded by illiteracy, poverty and rapid growth of the human population. Promoting awareness campaigns is the best to counter challenges in forest conservation. Men should not be taken to be sole decision makers, which in turn hinders the implementation of forest conservation measures. Women should be incorporated in the decision making process.

\section{Keywords}

Household Factors, Forest Conservation Strategies, Community Awareness, Implementation Strategies, Social and Cultural Factors

\section{Introduction}

Forest resource utilization poses a major challenge to the delicate balance between complex-fragile ecosystems in many developing countries. Forests in such economies are major sources of livelihood for the rural communities who depend on forest resources for fuel wood, construction material and livestock grazing, among others (Barbier \& Burgess, 2001). The extraction of biomass in the form of forest products like timber, fuel wood and fodder alters wildlife habitat and constitutes one of the most important threats to forests and wildlife (Fashing, Forrestes, Scully, \& Cords, 2004). Other factors associated with the increase in forest degradation broadly include demographic, economic, institutional and technological factors (Fischlin, Ayres, Kamosky, Kellomarki, Louman, Ong, Plattner, Santoso, Ian Thompson, Booth, Marcar, Scholes, Swanston, \& Zamolodchikor, 2009).

Stem (2006) observed that deforestation contributes at least $18 \%$ of man-made carbon dioxide emissions, and that while forest conservation is allowed for industrialized countries in the Kyoto protocol, it is not permitted for developing countries where most deforestation occurs. He therefore proposed avoided deforestation as one of the four key "elements" of a global climate change mitigation strategy, arguing that it would be a highly cost effective way of reducing greenhouse gas emissions fairly quickly.

Environmental protection was initiated where some natural forests were designated as logging ban areas. However, the conservation policies were short lived. There have been cases in which local forests agencies have demarcated potential nature reserves without going into the field to access tenure (Schabel, 1990). Insufficient government funding for the operation of nature reserves has resulted in increasing activities to raise revenue, such as tourism development, and even the use of natural resources (Barbier \& Burgess, 2001).

The history of control of Kenya forests by the government for conservation purposes dates as far as the colonial period. By 1908, the colonial government had put all the major forest areas in the country under the control of the government. The colonial government emphasized that, the public goal was best served through the protection of forest and water resources even if this meant 
the displacement of the local communities (Kamugisha, Ogutu, \& Stahl, 1997). The management of forest resources in Kenya is guided by the national forest policy supported by the forest act (Wass, 1995). There are existing conflicts between the objectives of conservations programs and those of the local communities (Ghai, 1994; Salafsky \& Wollenberg, 2000). This has been the biggest hindrance in conservation efforts (Mugenda \& Mugenda, 1999).

After World War I during British rule commercial tea cultivation, expanded resulting in more forests clearance. Some new forests reserves were established because of catchment values (Kerlinger, 2000). After independence in 1961, regulations over natural resources were relaxed partly due to the government decreased capacity to enforce regulations and partly as a result of government policy (Hamilton \& Bensfed-Smith, 1989). The cultivation of the Cardamom-a valuable cash crop which spread from 1950', had serious deteriorating effects to the forests (Iversen, 1991).

\section{Statement of the Problem}

Forests play many important roles in the ecosystem. They provide direct benefits to communities around them and act as habitat for various plant and animal species. Nandi forest is one of the most unique forests in Kenya. The forest is home to numerous plants and animal species. This forest reserve is one of the many forests extensively disturbed by human activities. A conflict of interest exists between the local community attempts to meet their forests needs and the initiatives to conserve and effectively manage the forest and its environs by government officials. In 1968, Sessional Paper no. 1 Act 385, the colonial act was slightly modified to cater for post-independence era. The local government, under the local Councilor was given the mandate of preserving and protecting forests under her jurisdiction. This therefore meant that the local authority and the Chief Forest Conservator were in-charge of conservation activities. The exercise of these powers had the effect of alienating people from the forests and people ceased to care for them and failed to see any responsibility over forest resources. In an effort to curb widespread deforestation, Government of Kenya came up with Forestry Master Plan 1998. This master plan was a result of Forest Act 1998, which proposed several methods for conservation.

Despite its significance, the Nandi Forest complex still faces serious threat. Settlement into the forest has increased significantly in the last one decade owing to a number of factors (Fashing, Forrestes, Scully, \& Cords, 2004). New settlers clear the forest to make way for farming. At the same time the felling of trees for timber, building material, fuel wood and charcoal has increased with the increase in demand for these products (Muoria et al., 2003; Fashing, Forrestes, Scully, \& Cords, 2004; Owino et al., 2008). The success of conservation programmes largely depend on the capacity available in the County, particularly at the Forest Service. Capacity encompasses a number of aspects that include human resource, finances and equipment, which assist an organization to become stronger and more effective in meeting goals and objectives. Theoretically, 
households are expected to conserve forests if they are aware of the benefits of doing so. In particular, it is expected that awareness of the direct and indirect benefits of conserving the forests will affect how households utilize the forests. Therefore need to study on the evaluation of factors that affect the implementation of strategies for conserving South Nandi forest.

The study was guided by the following questions:

1) How do the household factors influence the implementation of conservation of South Nandi forest?

2) How does community awareness of forest conservation affect the implementation of forest conservation measures in South Nandi Forest?

3) What are the implementation strategies of forest conservation measures in South Nandi Forest?

4) To what extent do social and cultural factors influence the implementation of conservation of South Nandi forest?

The main objective of the was to establish household factors affecting the implementation of strategies in forest conservation of forests in South Nandi Forest Kenya:

1) To investigate how the household factors affect the implementation of conservation.

2) To establish how community awareness of forest conservation affect the implementation of forest conservation measures.

3) To examine the extent to which social and cultural factors affect the implementation of conservation.

4) To assess the implementation strategies of forest conservation measures.

\section{Literature Review}

\subsection{Household Factors and Forest Conservation}

Rural households are rarely the target of forest conservation efforts because their impact on the forest is a commutative results of millions of household resource management decisions, all of which are identifiable agents in forest conversion, and thus amenable to intervention (Bjondalein, 1992). Though forest clearing for household agriculture and forest resource extraction for household income generation may be the two most important factors driving forest degradation in the region the furtiveness of small decisions makes mitigation efforts exceedingly difficult.

An overemphasis on protected areas only credible conservation tool has not always been a good strategy. Under certain conditions it has even increased poverty. Although the percentage of the earth's surface devoted to protected areas are protected in name only and that many suffer from widespread illegal use, which in some cases is leading to loss of biodiversity. Carey, Dudley and Stolon (2000) along similar line to the economic development first approach, it has sometimes been argued that, the eradication should come first and that the environment can be addressed later, but the long term consequence of such an ap- 
proach are to be very serious (Fashing, Forrestes, Scully, \& Cords, 2004).

More than elsewhere, forests in the dry land of sub-Saharan Africa have the potential to contribute to poverty reduction and food security as long as they are well valued and sustainably managed. The inhabitants of these areas are mostly farmers, herders and forest product gatherers their livelihood are therefore largely dependent on forests and woodland services and forest management has to respond to their many and diverse needs. Poverty and environmental degradation are major problems in dry land sub-Saharan Africa, where forests and trees contribute significantly to rural livelihoods. An approach to conservation is that of treating local inhabitants not as destroyers of the forests who stand on the way of conservation programs but rather as constituent members of the forest ecosystem, who can perform positive role in the implementation of a conservation program (Barbier \& Burgess, 2001).

\subsection{Community Awareness and Forest Conservation}

If local people recognize how they benefit from products and services provided by forests, they will be motivated to modify their resources and land use practices and to invest time and effort in forest conservation activities. Given the right enabling environment and the right incentives, communities can and will manage forests and woodland resources for diversity (Kokwaro, 1988). In the pre-colonial period, local communities' conserved natural resources such as water springs and dry season grazing. This they did through development of rules, regulations and community sactions. Forests were also conserved for value other than the resources they contained; they provided refuge and often took a religious significance. The Miji Kenda community of the Kenyan coastal forests, for example protected Kaya Forests for religious reasons (Millon, 1955).

Communities often need to strengthen their organizational capacity in order to re-claim responsibilities in management and conservation of forest resources through education and other forms of capacity building. Educational awareness and capacity building can enhance the participation process. The educational process should run parallel to the actual roll out of the project so that in the process of drawing up plans, developing participatory tools the stakeholders can learn from each other. Appropriate educational processes should be used to mobilize prior and new knowledge and build competence among the community members. Preservation and conservation of environmental resources suggests positive and friendly attitude while the careless utilization of these resources suggests negative attitudes (Adams et al., 2011). The environmental policy of Ethiopia has recognized and identified environmental education and awareness as a key strategy to transform knowledge of environmental issues to the people

(BafToe, 2007).

\subsection{Implementation Strategies and Forest Conservation}

Land is being converted to alternative, non-forestry uses as indicated by the sta- 
tistics on deforestation. Cut-over lands are left idle and forests are degraded as local residents seek improvements in daily living if only temporarily achieved by land clearing, gathering of fuelwood, or premature harvesting for a subsistence income or personal local utilization (United Nations, Food and Agricultural Organization, 2006). In the most effective protected areas (in this case the Brazilian Amazon), almost 6 percent more forest cover would be safeguarded in comparison to unprotected land in the span of just one decade," according to a blog post by CIFOR that accompanied the release of the PLOS collection. "In the case of the least effective protected areas (in this case Indonesia), just 0.8 percent more forest cover would be preserved over a 10 -year period".

Börner and colleagues note in the overview study that "the global drop in rates of tropical tree cover loss is mostly driven by a few countries, such as Brazil," which is perhaps why the country received more scrutiny than most. A study in the collection that looked specifically at protected areas in the Brazilian Amazon found that they reduced deforestation by two percent, on average, between 2000 and 2008. "However these impacts vary over space and time," Börner and team write. "They find: 1) lower effectiveness of protection as annual rates of forest loss went down in the region as a whole over time, and 2), higher effectiveness of protected areas located close to cities and transport ways, where pressure on forest resources tends to be high (Barbier \& Burgess, 2001).”

Forest law enforcement and public disclosure of legal offenders were found to have contributed to reductions in annual forest loss of 0.13 and 0.29 percent, respectively (Balmford et al., 2002). A jurisdictional conservation approach that provided budgetary incentives to local governments in the Eastern Amazon, meanwhile, had more mixed results-the initiative helped reduce deforestation rates in some years, but not in every year studied.

\subsection{Social-Cultural Factors and Forest Conservation}

The influence of gendered relationships on access to forests and on forests sustainability remains a concern for scholars and practitioners. Approaches to forest management the world over have undergone profound changes from central state control to the 70's through community based approaches of the 80 's and the devolution of 90's. Women involve in a range of independent variable. In addition to this the security of women's property rights and access to forest and tree resources serve as an important incentive for their adopting resource conservation measures. In addition, because they are the ones responsible for feeding the family they are most likely to be burdened by deteriorating forest condition and thus have a tendency to conserve in order to mitigate hardship. Men are largely involved in timber extraction and have less frequent involvement in forest unlike women who use products e.g. firewood, NTFP and are more likely to be in the forest more often, which is an aid for monitoring (Fashing, Forrestes, Scully, \& Cords, 2004).

The main gender mainstreaming aspects incorporated include issues of gend- 
er empowerment where under social framework women's workload is to be reduced through introduction and popularization of modem and appropriate technology and by impacting decision making has hardly kept pace with the earlier changes and they don't seem to fare any better under devolution programs (Fashing, Forrestes, Scully, \& Cords, 2004). In a study across 12 countries in Africa, Asia and Latin America, Kokwaro (1988) hypothesized that where resources users regularly monitor and sanction resource use the condition of forest resources or more specifically, the commercial and subsistence values of forests as perceived by both users and forest authorities, will likely be better than where rules are not enforced.

It is generally recognized that forests are important for the poor, majority of whom are women, and who often do not own land but do use forest resources for subsistence, as safety nets and even to generate modest incomes. Women are critical actors in management of forest resources. Relative participation of men and women in various capacities of decisions making have been the key items under study. Millennium Ecosystem Assessment (2005) observes that women are often excluded from participation for various reasons including; the rules governing the community forestry groups, social barriers stemming from cultural constructions of gender roles, responsibilities and expected behavior, logistical barriers relating to the timings and length of organizational meetings and male bias in the attitudes of those promoting community forestry initiatives.

\subsection{Theoretical Framework}

\subsubsection{Functionalist Theory}

Functionalism is a framework that sees society as a complex system whose parts work together to promote solidarity and stability. In this way, society is like an organism and each aspect of society (institutions, social constructs, etc.) is like an organ that works together to keep the whole functioning smoothly (Krasny, 2009). This approach looks at society through a macro-level orientation, which is a broad focus on the social structures that shape society as a whole. Functionalism addresses society in terms of the function of its constituent elements: norms, customs, traditions and institutions. Functionalists, in general, identify a number of functions families typically perform: reproduction; socialization; care, protection, and emotional support; assignment of status; and regulation of sexual behavior through the norm of legitimacy.

Functionalism interprets each part of society in terms of how it contributes to the stability of the whole society. Society is more than the sum of its parts; rather, each part of society is functional for the stability of the whole (Krasny, 2009). Durkheim actually envisioned society as an organism, and just like within an organism, each component plays a necessary part, but none can function alone, and one experiences a crisis or fails, other parts must adapt to fill the void in some way.

Within functionalist theory, the different parts of society are primarily composed of social institutions, each of which is designed to fill different needs, and 
each of which has particular consequences for the form and shape of society (Sanderson \& Huron, 2011). The parts all depend on each other. The core institutions defined by sociology and which are important to understanding for this theory include family, government, economy, media, education, and religion.

\subsubsection{Nature's Template Theory}

Forests conservation as a part of environmental conservation directly or indirectly leads to sustainable development (Ndiritu \& Nyangena, 2011). According to Nature Template theory, forests form an important part of the environment. This is in reference to their composition, structure, function, and disturbance that regulate environmental patterns across space and time. According to Todaro and Smith (2006), forests are the natural endowment of any society. They provide resources that societies need including energy, water, purified air, shelter and food among other functions. The conservation of forests ensures a functional mutual ecosystem. Any mitigation strategies therefore as advanced by the Nature Template theory should mimic the natural forest replenishing processes as much as possible.

According to the theory, mitigation strategies should be designed in a way that follows the natural forest cover recovery processes. More so, forest encroachment activities should also resemble the natural forest ecosystem disturbances' as closely as possible. However in the modern times, it is impossible to do this precisely. Nevertheless, it is quite possible to choose forest management forms that are relatively similar to natural disturbances. These include activities that, help to reduce pressure on forest resources such as emphasis on agro forestry, use of alternative energy sources and exploration of alternative income sources e.g., forest- friendly small-scale enterprises.

\section{Methodology}

\subsection{Research Design}

The research design for this study was a descriptive survey. In view of this, the study adopted the field survey method to collect both quantitative and qualitative data. The field survey implies the process of gaining insight into the general picture of a situation, without utilizing the entire population (Gall, Borg, \& Gall, 1996: p. 28).

\subsection{Target Population}

The target population for this study constituted of household members aged 18 years and above living around Nandi South Forest. South Nandi shows that there are approximately 63,206 households who formed the target population for the study.

\subsection{Sample Size}

Nandi forest is surrounded by 18 administrative locations overseen by chiefs. 
Out of the 18 locations, 12 were randomly sampled for the study. The study aimed at drawing a sample of 120 unit of observation from these locations.

\subsection{Data Analysis}

Qualitative data generated from open-ended questions was analyzed in themes, content analysis and categories identifying similarities and differences that emerged. Qualitative analysis includes analysis of what some respondents said in the open ended questions. Quantitative data was scrutinized for completeness, accuracy and uniformity. Data from questionnaires were analyzed using descriptive statistics, and came out with frequencies and percentages using Statistical Package for Social Sciences (SPSS) - this is the reliable tool for quantitative data analysis.

\section{Findings and Discussions}

\subsection{Community Awareness and Forest Conservation}

\section{Seminar attended on forest conservation}

$61.7 \%$ indicated that they have never attended any training on forest conservation while $38.3 \%$ have attended. This implies that the majority have no training on forest conservation which makes it difficult for the forest to be conserved (Figure 1).

The study aimed to find out what those who have attended the training have been trained on. The results indicates that they were trained on how to regulate and plan cutting of trees, control over forest fire, reforestation and afforestation, check over forest clearance for agricultural purposes, protection of forest, and proper utilization of forest products and forests.

\section{Conservative initiative involved before training}

From Figure 2, 61\% have never been involved in any conservation initiative while $39 \%$ have. This implies that a lot needs to be done on the training on forest conservation and more should be involved in the conservation initiatives.

On whether there exists civic education in the community of forestry matters $68 \%$ of the respondents were of then opinion that they are minimal. $10 \%$ agreed that they do exist while $22 \%$ were of the opinion that they do exist. When they were asked to mention some of the groups that facilitate above, 30 percent of the respondents that had accepted mentioned KFS, Other 45\% mentioned about NGO'S, $20 \%$ of the respondents mentioned of Community Groups while 5\% mentioned of other institutions and partners in the community such as Provincial administration, Church and schools.

\section{Rating the training}

From Table 1, 31.7\% of the respondents indicated that the training is very useful, $29.3 \%$ indicated that it's useful, $22.0 \%$ indicated that it's not very useful, while $17.0 \%$ indicated that its average. This implies that more of training should be done to educate people about the importance of forests, the need to conserve them and how to conserve them. 


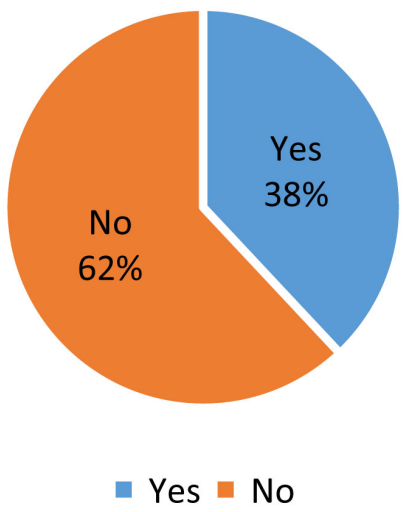

Figure 1. Seminar attended on forest conservation.

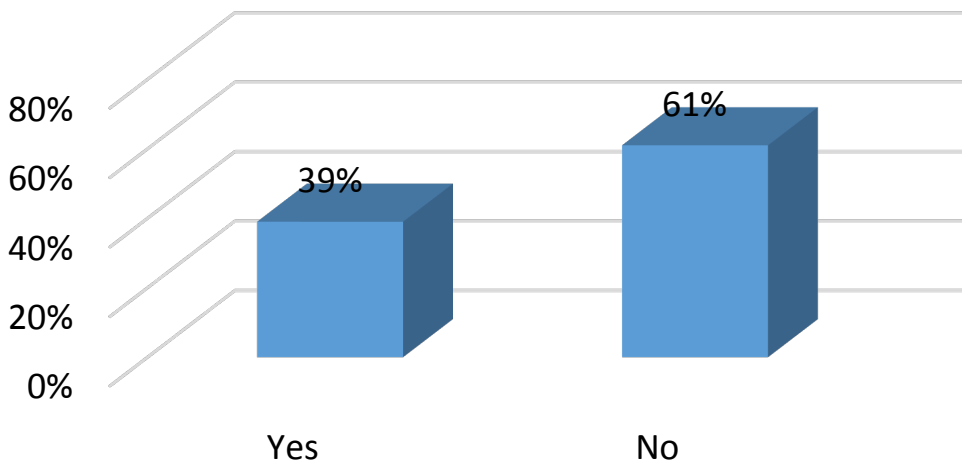

Figure 2. Conservative initiative involved before training.

Table 1. Rating the training.

\begin{tabular}{ccc}
\hline Rating & Frequency & Percent \\
\hline Very useful & 13 & 31.7 \\
Useful & 12 & 29.3 \\
Average & 7 & 17.0 \\
Not very useful & 9 & 22.0 \\
Total & 41 & 100 \\
\hline
\end{tabular}

\section{Level of motivation to conserve forests}

From Table 2, 30.1\% of the respondents indicated that the motivation is high, $27.7 \%$ indicated that the motivation is moderate, $24.1 \%$ indicated that it's low while $18.1 \%$ noted that it's very high. This implies that for forest conservation to be effective, more motivation is needed.

\subsection{Implementation Strategies and Forest Conservation}

\section{Member of community forest association}

From Table 3, 74.3\% of the respondents indicated that they are not members of the community forest association while $25.7 \%$ are. This implies that it's difficult to conserve the forest since the majority of the community members 
Table 2. Level of motivation to conserve forests.

\begin{tabular}{ccc}
\hline Level of motivation & Frequency & Percent \\
\hline Very high & 15 & 18.1 \\
High & 25 & 30.1 \\
Moderate & 23 & 27.7 \\
Low & 20 & 24.1 \\
Total & $\mathbf{8 3}$ & 100.0 \\
\hline
\end{tabular}

Table 3. Response whether respondent is a member of community forest association.

\begin{tabular}{ccc}
\hline Response & Frequency & Percent \\
\hline Yes & 26 & 25.7 \\
No & 75 & 74.3 \\
Total & 101 & 100.0 \\
\hline
\end{tabular}

does not belong to the association hence they know little regarding forest conservation. According to the chairman, Kobasoi community forest association (CFA), there is little incentive for community members to join the association because of low benefits majorly subsistence which the community can still access without being members of the community forest association.

\section{Major challenges on implementation of forest conservation measures}

According to Table 4, 54\% of the respondents indicated that logging is a major challenge, while $46 \%$ indicated that grazing and encroachment is major challenge. This implies that something needs to be done to curb logging since it's the major challenge on the implementation of forest conservation measures.

The major forest threat is forest fires. The forest fires are majorly caused by the Charcoal burners, honey harvesters, Land clearance and other careless practices in the shamba farms alongside ignorance aspects of burning the forest to prompt the onset of the rains. The other threat is logging which majorly target on the poles for: Fencing, construction of the houses, and selling for commercial services. Charcoal burning is another major vice whereby, it is done majorly for commercial services. Around the market areas, you would largely experience women selling charcoal in tins. Other challenges are due to financial constraints and few forest officers/stations to intensify patrols.

Dealing with the challenges in order to implement forest conservation measures

According to Table 5, 58.8\% of the respondents indicated that involving local communities in forest conservation will be the best way to deal with the challenges, $19.6 \%$ indicated that the challenges should be tackled through forest conservation campaign, $17.5 \%$ felt that there should be better forest legislation while $4.1 \%$ felt that there is need to prosecute/sacking of inefficient forest officers. This implies that for better handling of the challenges on implementation of forest conservation measures there should be full involvement of local community in forest conservation. 
Table 4. Major challenges on implementation of forest conservation measures.

\begin{tabular}{ccc}
\hline Challenges on implementation & Frequency & Percent \\
\hline Grazing & 23 & 23.0 \\
Encroachment & 23 & 23,0 \\
Logging & 54 & 54.0 \\
Total & 100 & 100 \\
\hline
\end{tabular}

Table 5. Dealing with the challenges in order to implement forest conservation measures.

\begin{tabular}{ccc}
\hline Dealing with challenges of conservation & Frequency & Percent \\
\hline Through forest conservation campaign & 19 & 19.6 \\
Involving local communities in forest conservation & 57 & 58.8 \\
Better forest legislation & 17 & 17.5 \\
Prosecution/sacking of inefficient forest officers & 4 & 4.1 \\
Total & $\mathbf{9 7}$ & $\mathbf{1 0 0 . 0}$ \\
\hline
\end{tabular}

Method of communication through which information regarding forest conservation strategies is gotten

From Table 6, 67\% of the respondents indicated that information is gotten through barazas (community gathering), 19.4\% through radio (local channel), $5.8 \%$ through letters and memos, $4.9 \%$ through newspapers, while $2.9 \%$ through medicine extraction. This implies that barazas are the ideal method of communication through which information regarding forest conservation is gotten.

\subsection{Involvement in Planning and Implementation of Forest Conservation Activities}

According to Table 7, 56.6\% of the respondents have never been involved in planning and implementation of forest conservation activities while $43.3 \%$ have. This implies that a lot needs to be done to make sure that many people are involved in planning and implementation of forest conservation activities.

\section{Ways of planning and implementation of forest conservation activities}

From Figure 3, 86.1\% of the respondents indicated that planting of trees is one the best ways of planning and implementation of forest conservation activities, $11.6 \%$ indicated protection and patrols while $2.3 \%$ mentioned pruning and trimming. This implies that tree planting is the best way of planning and implementation of forest conservation activities.

\section{Involvement in forest based income generating activities}

From Table 8, 59.4\% of the respondents are not involved in any income generating activities in the South Nandi forest while $40.6 \%$ are. This implies that with more efforts from the relevant authorities it's easy to converse the forest.

Forest based income generating activities

From Figure 4, 69.2\% of the respondents indicated that they were more 
Table 6. Method of communication through which information regarding forest conservation strategies is gotten.

\begin{tabular}{ccc}
\hline Methods of communication & Frequency & Percent \\
\hline Letters and memos & 6 & 5.8 \\
Radio (local channel) & 20 & 19.4 \\
For medicine extraction & 3 & 2.9 \\
Barazas (community gathering) & 69 & 67.0 \\
Newspapers & 5 & 4.9 \\
Total & 103 & 100 \\
\hline
\end{tabular}

Table 7. Involved in planning and implementation of forest conservation activities.

\begin{tabular}{ccc}
\hline Response & Frequency & Percent \\
\hline Yes & 43 & 43.4 \\
No & 56 & 56.6 \\
Total & 99 & 100.0 \\
\hline
\end{tabular}

Table 8. Response whether the respondents are involved in forest based income generating activities.

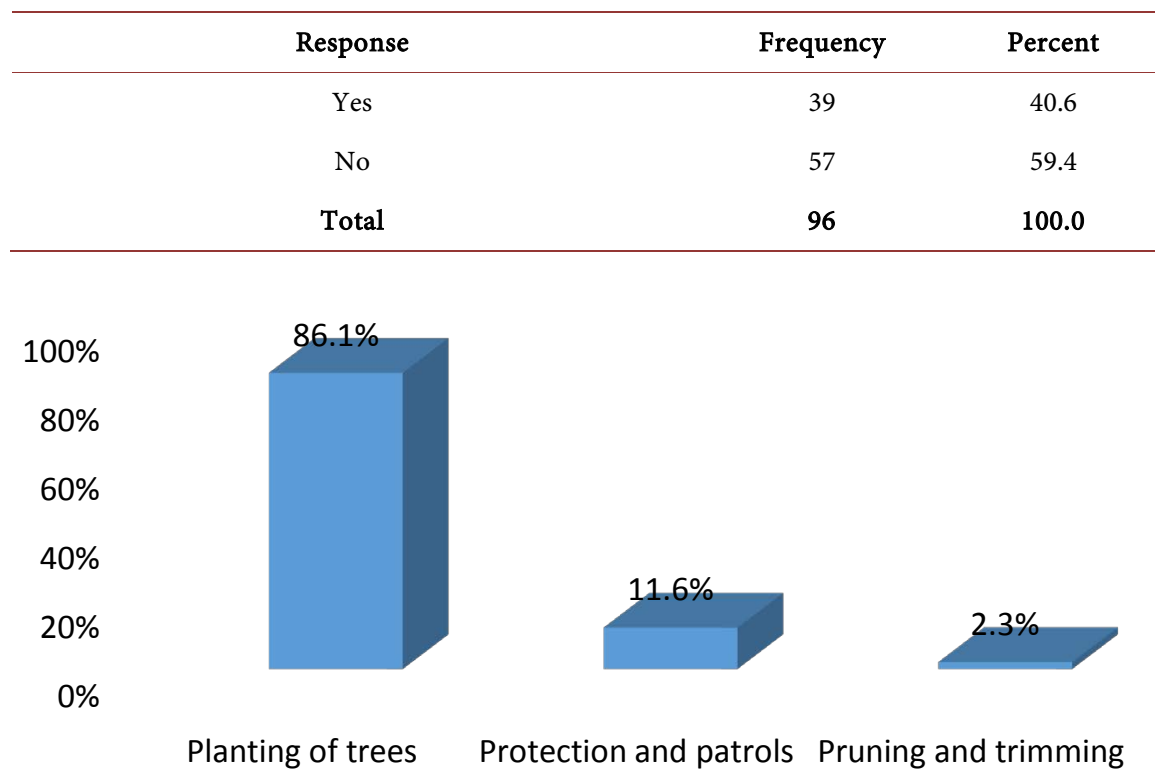

Figure 3. Ways of planning and implementation of forest conservation activities.

engaged in bee keeping as a forest income generating activity, $25.6 \%$ indicated guiding of tourists, $3.2 \%$ Cottage/tourist huts and $2.7 \%$ herbal medicine. This implies that through forest conservation and proper management the forest can be very beneficial to many that stay around without destroying it.

\section{Membership in environmental group}

According to the findings as shown in Table 9, $61.2 \%$ of the respondents are not members of any environmental group while $39 \%$ are. This implies that 


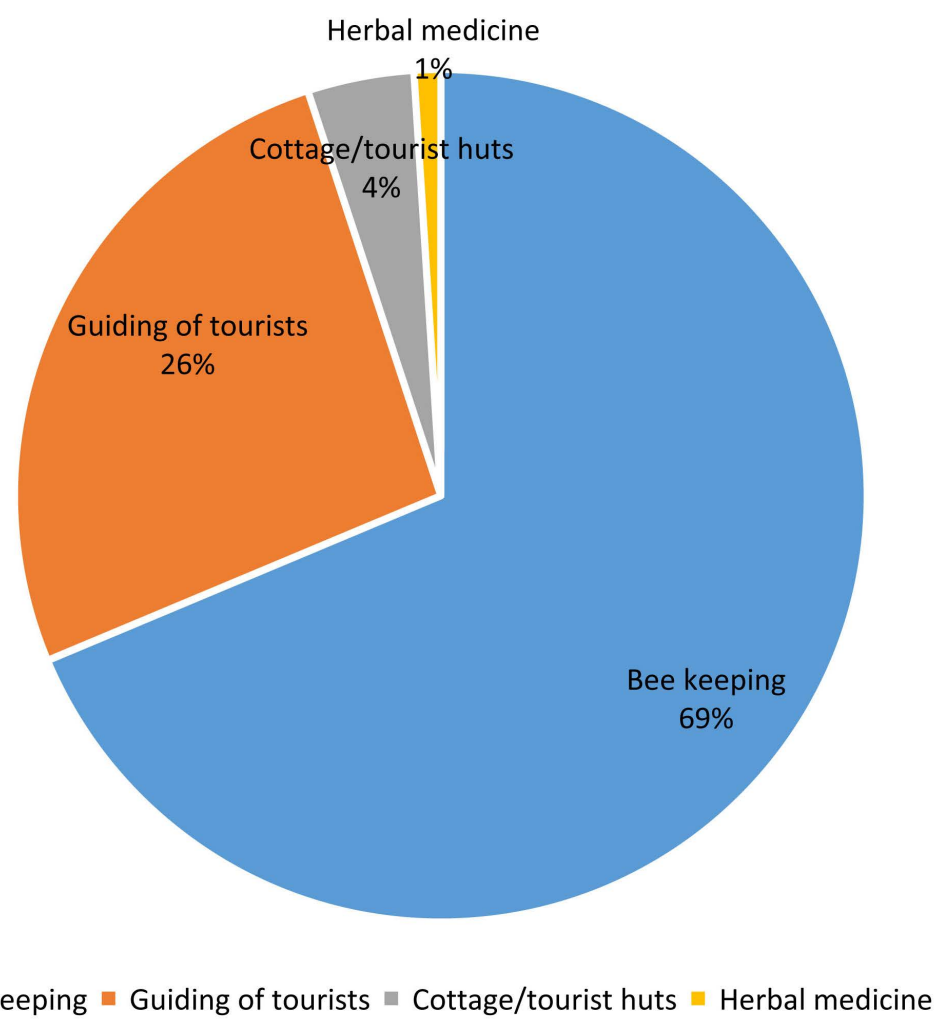

- Bee keeping $\|$ Guiding of tourists $=$ Cottage/tourist huts $\|$ Herbal medicine

Figure 4. Forest based income generating activities.

Table 9. Response whether residents belong to any environmental group.

\begin{tabular}{ccc}
\hline Response & Frequency & Percent \\
\hline Yes & 38 & 38.8 \\
No & 60 & 61.2 \\
Total & $\mathbf{9 8}$ & $\mathbf{1 0 0}$ \\
\hline
\end{tabular}

through the $38.8 \%$ the local authorities can use it to enlighten the community on the importance of forest conservation.

\section{Environmental group activities}

From Figure 5, 65.8\% of the respondents noted that they are involved in tree planting, $31.6 \%$ are involved in management of the nursery and $2.6 \%$ are involved in monitoring of flora and fauna (plant and animals).

From Table 10, 67.3\% of the respondents have never been involved in election/selection of environmental or community forest association officials/leaders from your community while $32.7 \%$ have been.

\subsection{Social-Cultural Factors and Forest Conservation}

\section{Challenges in implementation of forest conservation measure}

Deforestation through illegal logging; charcoal burning; and the encroachment of forests for human settlement and agriculture. These problems are compounded by illiteracy, poverty and rapid growth of the human population. To 


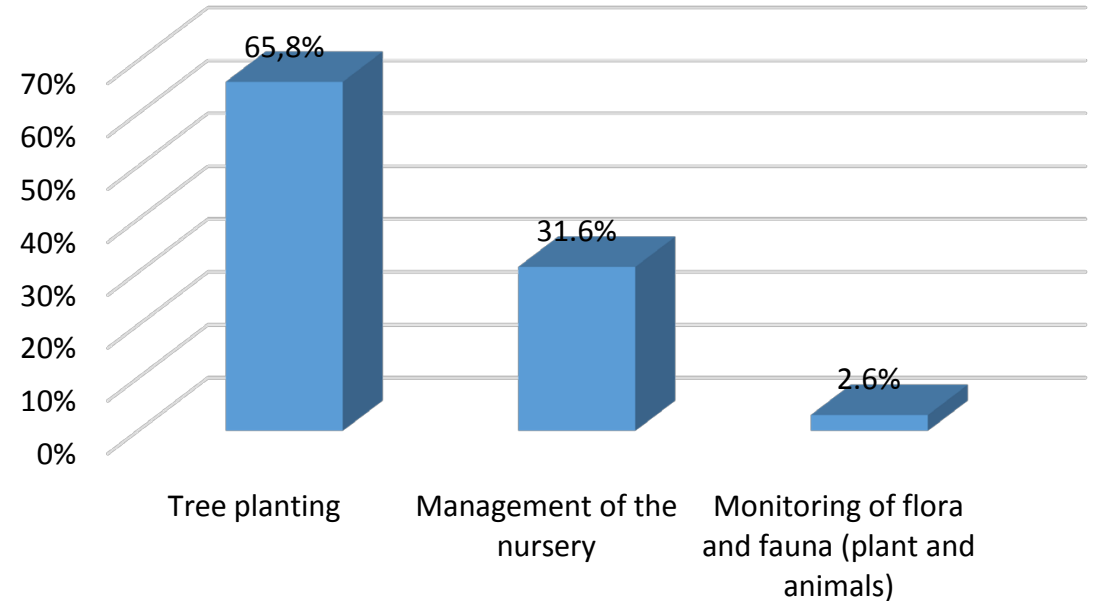

Figure 5. Environmental group activities.

Table 10. Involved in election/selection of environmental or community forest association officials/leaders from your community.

\begin{tabular}{ccc}
\hline Response & Frequency & Percent \\
\hline Yes & 33 & 32.7 \\
No & 68 & 67.3 \\
Total & 101 & 100.0 \\
\hline
\end{tabular}

counter the challenges there is need for: strong legislation, for example the Forest Act 2005, and subsidiary regulations, for example charcoal Rules, political goodwill and support, communication and awareness creation among communities, poverty alleviation and job creation among forest adjacent communities.

\section{Ways of overcoming the challenges}

$60.8 \%$ of the respondents indicated that promoting awareness campaigns is the best way to overcome the challenges, $29.9 \%$ involving youth in forest conservation through education and training, $8.3 \%$ support women participation while $1 \%$ voting women in power. This implies that promoting awareness campaigns is the best to counter challenges in forest conservation.

\section{Land ownership}

From Table 11, 53.5\% indicated that land is owned by men only, 35.6\% women and men jointly, $6.9 \%$ communal, while $4 \%$ women only. This implies that land is largely owned by men in Nandi South.

Cultural beliefs and their influence in implementation of forest conservation measures

From Table 12, 59.6\% of the respondents noted that male are the sole decision makers which is the highest influence in the implementation of forest conservation, $17.2 \%$ females role is in the kitchen, $14.1 \%$ females are like property in a home, while $9.1 \%$ noted that males are allowed to plant and cut trees. From the findings, this implies that men are taken to be a sole decision maker which in turn hinders the implementation of forest conservation measures. 
Table 11. Response on who among family members own the land.

\begin{tabular}{ccc}
\hline Family members who own the land & Frequency & Percent \\
\hline Women and men jointly & 36 & 35.6 \\
Women only & 4 & 4.0 \\
Men only & 54 & 53.5 \\
Communal & 7 & 6.9 \\
Total & 101 & 100.0 \\
\hline
\end{tabular}

Table 12. Major cultural belief influencing implementation of forest conservation measures.

\begin{tabular}{ccc}
\hline Major cultural beliefs influencing conservation & Frequency & Percent \\
\hline Females roles are in the kitchen & 17 & 17.2 \\
Males are the ones allowed to plant or cut trees & 9 & 9.1 \\
Males are the sole decision makers on family matters & 59 & 59.6 \\
Females are viewed as property in a home & 14 & 14.1 \\
Total & 99 & 100.0 \\
\hline
\end{tabular}

The Community has been empowered through Public Barazas where they meet all the stakeholders including all the Departmental Heads and the Provincial Administration like the Chiefs, Do's, and DC. The Community is enlightened about the need to conserve the Forest while the provincial Administration as well is treated as agents to propagate the same information through other meetings like public Holidays. The world environmental Day and Labor Day are the Key events that mark the Celebration and sensitization on Forest Conservation. Awareness is also made by distributing brochures and other publications, media through Radio marketing programs.

\section{Participants in forest conservation}

From Figure 6, 75.6\% of those that participate more in forest conservation activities are groups, $12.1 \%$ are men, and $10.1 \%$ are the youth while $2 \%$ are the women. This implies that the women have been given a lesser hand in forest conservation which needs to be looked unto to make sure equal representation.

\section{Forest utilization for socio-cultural events}

The respondents were asked to indicate the socio-cultural events that are carried by the local community in the forest.

According to the findings, $95 \%$ of the respondents indicated that the forest is mostly used for initiation events, $4 \%$ sacred site and $1 \%$ traditional sacrifice. This implies that majority the forest is useful for initiation socio-cultural events (Figure 7).

\section{Conclusions and Recommendations}

\subsection{Conclusions}

From the study, the conclusions based on the findings were drawn. As proven by 


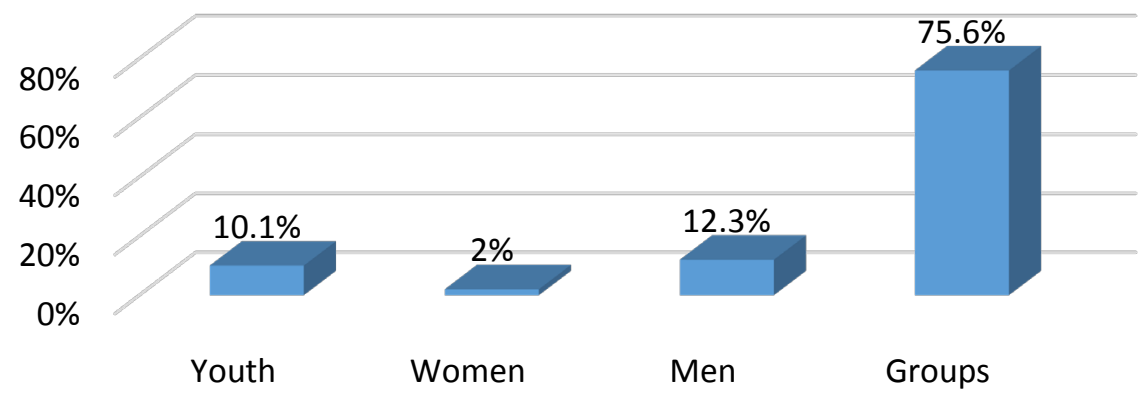

Figure 6. Participants in forest conservation.

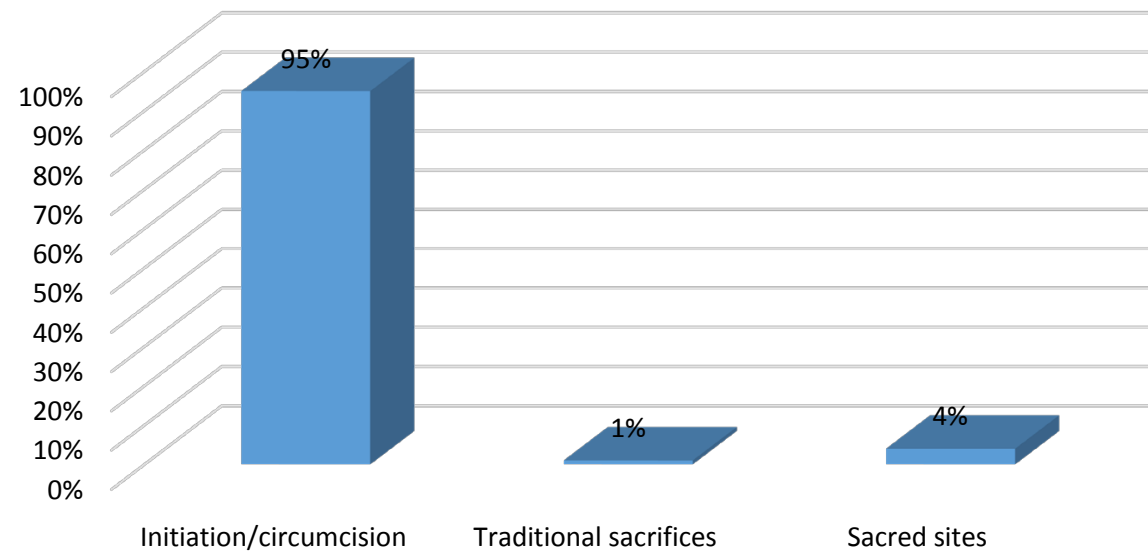

Figure 7. Forest utilization for socio-cultural events.

past studies and based on the study findings, it can be concluded that level of income and level of education remain the major challenges to implementation of forest conservation measures. Poor income or lack of regular income leads the communities living next to the forest to turn to the forest to a living leading to its destruction. Level of education determines the level of exposure and by extension of the importance of forest conservation. Education or awareness would make the local communities living next to the forest to easily understand the importance of afforestation and re-afforestation, that is, sustainable management of forest.

Lack of communication between the government through its agents and the communities led to these communities not owning the forest but treat is as governments. The study has also shown that policies and laws governing forest conservation are not clear to the communities leading to massive destruction of forests. The study showed that culture and laws of the communities living next to the forest may affect positively or negatively the implementation of conservation of forests. It was found that women in some communities are not allowed to plant trees and this is made worse by the fact that most of the land is owned by men. Therefore, men are the ones who decide on what is to be planted and who plants.

The study established that community awareness has a significant influence on participation of community members in forestry projects. These findings 
agree with those of Persha et al. (2011) who concluded that if local people recognize how they benefit from products and services provided by forests, they will be motivated to modify their resources and land use practices and to invest time and effort in forest conservation activities. The findings are also consistent with Wuletao (2008), who found that environmental policy recognized and identified environmental education and awareness as a key strategy to transform knowledge of environmental issues to the people. The study also found out that majority of the respondents were involved in conservation activities before they underwent any training and these findings agreed with Kabuye (1999) who found that indigenous knowledge and management are often used to conserve and in some cases enhance bio-diversity since it uses readily available management science that is better adapted to serve the needs of ecological sustainability. Cultural knowledge and management systems also include regimes to sustainable harvesting and processing of materials from individual species.

\subsection{Recommendations}

$\checkmark$ Influence of level of income on implementation of forests conservation measures in South Nandi Forest; the study established that most communities living next to the forest are either youth who have no source of regular income. In response to this problem, the study recommends that government should come up with youth empowerment programs which train and educate especially in enterprise management with more emphasis on effective use of acquired funds. This may store them from forest destruction.

$\checkmark$ Influence of implementation strategies; the study revealed that majority of the communities living next to the forest are school dropouts hence are poor and do not understand the importance of conservation. More men than women were uneducated yet they stand to gain more if forests were conserved. To effectively play its role in conservation, the study recommended that forest conservation be strategically included and examined under the various curricula of different learning institutions in Kenya. The study also suggest the need to communicate and disseminate information to communities living next to the forest so that they are made aware of every government program any and any difficulties being experienced in the delivery of the programs. Also the communities should be made aware of the benefits of conservation of forests and the negative impact that result due to destruction of forests.

$\checkmark$ Social-cultural factors and forest conservation; the study established that most communities are still engrossed in their cultures regarding forests in terms of food medicine for various illness and place of worship or shrine. This does not include conservation of forests. The study also revealed that women are prohibited from planting trees and that they do not own land yet they need forests more than men for provision of firewood and water. In response to these problems, there is need to educated communities of the im- 
portance of embracing modem culture while only retaining only progressive cultures. A mind shift among spouses especially among men should also be encouraged so that they give full support in forest conservation as well as management of forest products.

\section{Conflicts of Interest}

The author declares no conflicts of interest regarding the publication of this paper.

\section{References}

Adams, P. J. et al. (2011). Non-Native Species Impacts on Pond Occupancy by an Anuran. Journal of Wildlife Management, 75, 30-35. https://doi.org/10.1002/jwmg.29

BafToe, A. (2007). Addressing Conservation Community Concerns in Forest Management in West and Central Africa. Ecology and Society, 23, 21-25.

Balmford, A. et al. (2002). Economic Reasons for Conserving Wild Nature. Science, 297, 950-953. https://doi.org/10.1126/science.1073947

Barbier, E. B., \& Burgess, J. C. (2001). The Economics of Tropical Deforestation. Journal of Economic Surveys, 15, 413-433. https://doi.org/10.1111/1467-6419.00144

Bjondalein, E. R. (1992). Tanzania's Vanishing Rain Forests-Assessment of Nature Conservation Values, Biodiversity and Importance for Water Catchment. Biotic Diversity in Agroecosystems, 40, 313-334. https://doi.org/10.1016/B978-0-444-89390-1.50024-X

Carey, C., Dudley, N., \& Stolton, S. (2000). Squandering Paradise? The Importance and Vulnerability of the Worlds Protected Areas. Gland, Switzerland.

Fashing, P., Forrestes, A., Scully, C., \& Cords, M. (2004). Long-Term Tree Population Dynamics for the Conservation of the Kakamega Forest, Kenya, Biodiversity and Conservation. Biodiversity \& Conservation, 13, 753-771.

Fischlin, A., Ayres, M., Kamosky, D., Kellomarki, S., Louman, B., Ong, C., Plattner, G. K., Santoso, H., Ian Thompson, I., Booth, T. H., Marcar, N., Scholes, B., Swanston, C., \& Zamolodchikor, D. (2009). Future Environmental Impacts and Vulnerabilities. Adaptation of Forests and People to Climate Change: A Global Assessment Report.

Gall, M. D., Borg, W. R., \& Gall, J. P. (1996). Education Research: An Introduction. New York: Longman Publishers.

Ghai, D. (1994). Environment, Livelihood and Empowerment. Development and Change, 25, 1-11. https://doi.org/10.1111/j.1467-7660.1994.tb00507.x

Hamilton, A. C., \& Bensfed-Smith, S. R. (Eds.) (1989). Forest Conservation in East Usanbara Mountains, Tanzania. Gland and Cambridge: IUCN.

Iversen, T. I. (1991). The Usambara Mountains. North Eastern Tanzania: History, Vegetation and Conservation.

Kamugisha, J. R., Ogutu, Z. A., \& Stahl, M. (1997). Parks and People-Conservation and Livelihoods at Crossroads. Nairobi: Regional Soil Conservation Unit (RSCU).

Kerlinger, F. N. (2000). Foundations of Behavioral Research. San Diego, CA: Harcourt College Publishers.

Kokwaro, J. O. (1988). Conservation Status of Kakamega Forest in Kenya; The Easternmost Relic of the Equatorial Rainforest of Africa. Monographs in Systematic Botany of the Missouri Botanical Garden, 25, 471-489. 
Krasny, M. E. (2009). Garden Mosaics Final Report. Unpublished Report to the National Science Foundation Informal Science Education Program.

Millennium Ecosystem Assessment (2005). Nature's Services: Societal Dependence on Natural Ecosystems. Washington DC: Island Press.

Millon, R. F. (1955). Trade, Tree Cultivation, and the Development of Private Property in Land. American Anthropologist, 57, 698-712.

https://doi.org/10.1525/aa.1955.57.4.02a00040

Mugenda, O. M., \& Mugenda, A. G. (1999). Research Methods: Quantitative and Qualitative Approaches. Nairobi: Acts Press.

Muoria, P. K., Karere, G. M., Moinde, N. N., \& Suleiman, M. A. (2003). Primate Census and Habitat Evaluation in the Tana Delta Region, Kenya. African Journal of Ecology, 41, 157-163.

Ndiritu, S. W., \& Nyangena, W. (2011). Environmental Goods Collection and Children's Schooling: Evidence from Kenya. Regional Environmental Change, 11, 531-542.

Owino, A. O., Amutete, G., Mulwa, R. K., \& Oyugi, J. O. (2008). Forest Patch Structures and Bird Species Composition of a Lowland Riverine Coastal Forest in Kenya. Tropical Conservation Science, 1, 242-264. https://doi.org/10.1177/194008290800100306

Salafsky, N., \& Wollenberg, E. (2000). Linking Livelihoods and Conservation: A Conceptual Framework and Scale for Assessing the Integration of Human Needs and Biodiversity. World Development, 28, 1421-1438. https://doi.org/10.1016/S0305-750X(00)00031-0

Sanderson, E. W., \& Huron, A. (2011). Conservation in the City. Conservation Biology, 25, 421-423. https://doi.org/10.1111/j.1523-1739.2011.01683.x

Schabel, H. G. (1990). Tanganyika Forestry under German Colonial Administration, 1891-1919. Forest and Conservation History, 34, 130-141.

https://doi.org/10.2307/3983902

Stem, N. (2006). Stem Review: The Economics of Climate Change. Cambridge: Cambridge University Press.

Todaro, M. P., \& Smith, S. C. (2006). Economic Development (8th ed.). Reading, MA: Addison-Wesley.

United Nations, Food and Agricultural Organization (2006). Global Forest Resource Assessment, Main Report 2005: Progress toward Sustainable Forest Management. Forestry Paper 147, Rome. http://www.fao.org

Wass, P. (1995). Kenya's Indigenous Forests: Status, Management and Conservation Gland. International Union for Conservation of Nature (IUCN). 